\title{
EPIPHRENIC DIVERTICULUM OF THE OESOPHAGUS COMPLICATED BY THE IMPACTION OF A FOREIGN BODY
}

\author{
BY \\ C. S. SADASIVAN AND A. UMAPATHY* \\ From the Thoracic Unit, General Hospital, Madras, India
}

(RECEIVED FOR PUBLICATION OCTOBER 20, 1961)

\begin{abstract}
Epiphrenic diverticulum of the oesophagus is rare. It occurs $5-10 \mathrm{~cm}$. above the diaphragm in the form of a pouch connected to the oesophageal lumen by a narrow stalk or neck. Dysphagia is the commonest chief complaint. Since exacerbation of the dysphagia by a foreign body impacted in such a diverticulum has not so far been reported, we present the following case.
\end{abstract}

\section{Case Report}

A 49-year-old woman from Trichur, Kerala, reported on March 7,1961, and complained of severe dysphagia of a week's duration. This started after she had eaten a meal which included mutton curry. The dysphagia was less severe two days later after she had regurgitated some food containing pieces of mutton. She could swallow liquids at the time of admission to hospital.

She was known to have been a slow eater since childhood. She had actually felt dysphagia for solids, and had recently formed the habit of macerating her food (mainly rice) in buttermilk or milk to facilitate swallowing. She never had pain or vomiting.

Apart from evidence of loss in weight and a mild anaemia, there was no other significant clinical finding.

Fluoroscopic examination with a barium swallow showed narrowing of the lowest $5 \mathrm{~cm}$. of the oesophagus with a small diverticulum arising from the middle of the narrowed segment and projecting to the left. The diverticulum measured $2 \mathrm{~cm}$. in diameter and $1.5 \mathrm{~cm}$. in length; the neck or mouth was $0.7 \mathrm{~cm}$. across (Fig. 1). The barium emptied from the diverticulum slowly. A foreign body inside was not suspected pre-operatively. Barium was held up in the oesophagus itself above the narrowed segment.

Oesophagoscopy showed proximal dilatation filled with food debris. The mucous membrane was pale and smooth. Lower down, marked "spasm" made examination of the diverticulum impossible.

The patient was given $350 \mathrm{ml}$. of blood to correct the anaemia and was operated on on March 15, 1961. A left thoracotomy was carried out through the bed of the seventh rib and the pulmonary ligament was

* Present address: Department of Surgery, Hammersmith Hospital, London, W.12. cut. The mediastinal pleura was incised and the oesophagus mobilized. There were dense adhesions at the oesophageal hiatus. The diaphragm was radially divided. No external pouching or diverticulum of the oesophagus was noted, but the cardia was hard. Since an additional indurated growth could not be ruled out by palpation alone, oesophagogastrectomy was carried out. Alimentary continuity was restored by oesophago-gastrostomy and a pyloroplasty was performed. The diaphragm was sutured, the hiatal sling being fixed to the sides of the stomach to prevent further herniation into the thorax. The chest was closed with a water seal drain from the pleura. The drain was removed on the third day. Post-operative recovery was uneventful.

\section{Pathological Findings}

The resected specimen was of interest. The oesophageal wall was thick, but externally no abnormality was seen. The index finger could not be passed through the oesophageal lumen into the stomach. However, from the stomach side it was possible, by exerting gradual pressure, to pass a finger into the oesophagus. A grating sensation was felt on the left lateral aspect of the cardia. The specimen was filled with a contrast medium and a radiograph was taken (Fig. 2). Later, it was divided along the lesser curvature and the right side of the oesophagus. A diverticulum

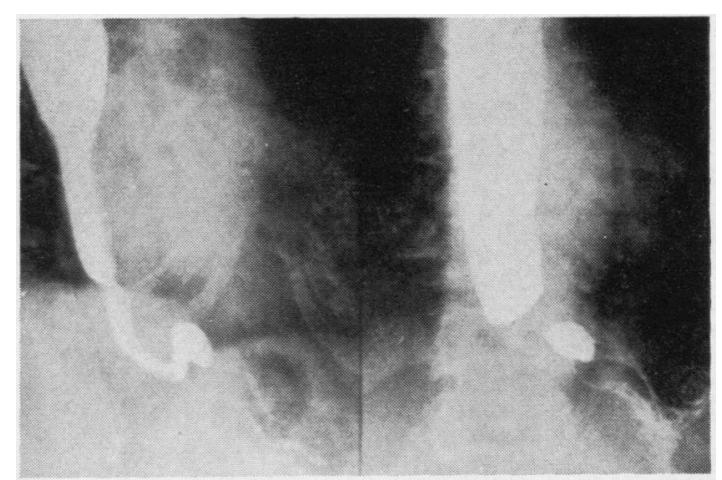

FIG. 1.-Barium swallow in oblique and P.A. views. 


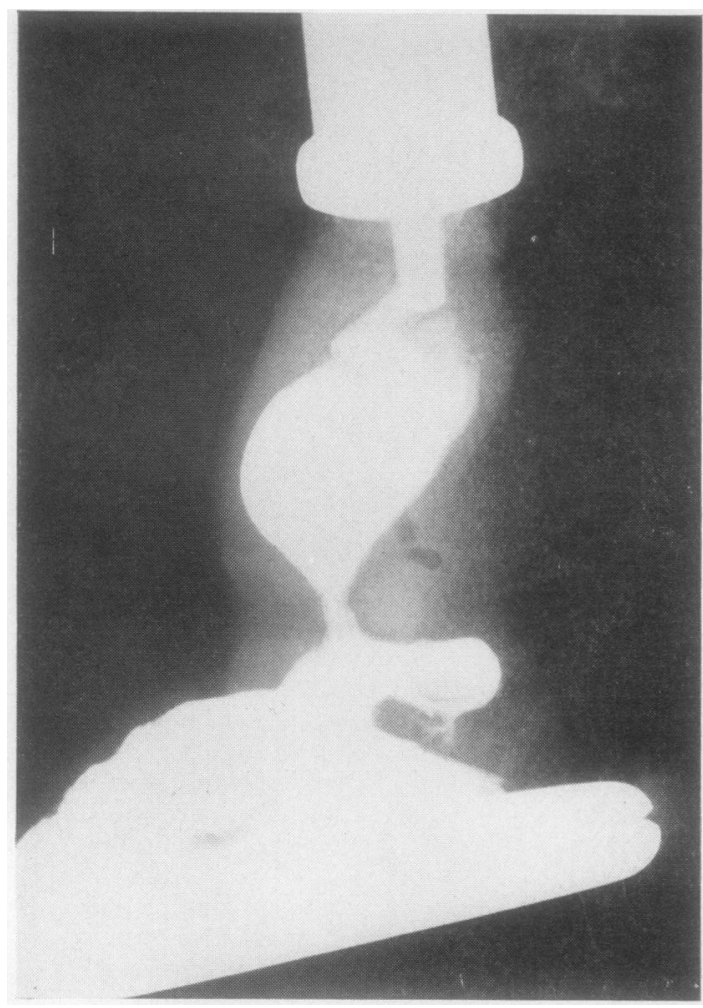

FIG. 2.-Rese: ted spe imen fiuced with buri.m. The fiving defect in the diverticultum and the thickness of the oesophagcal wall are seen.

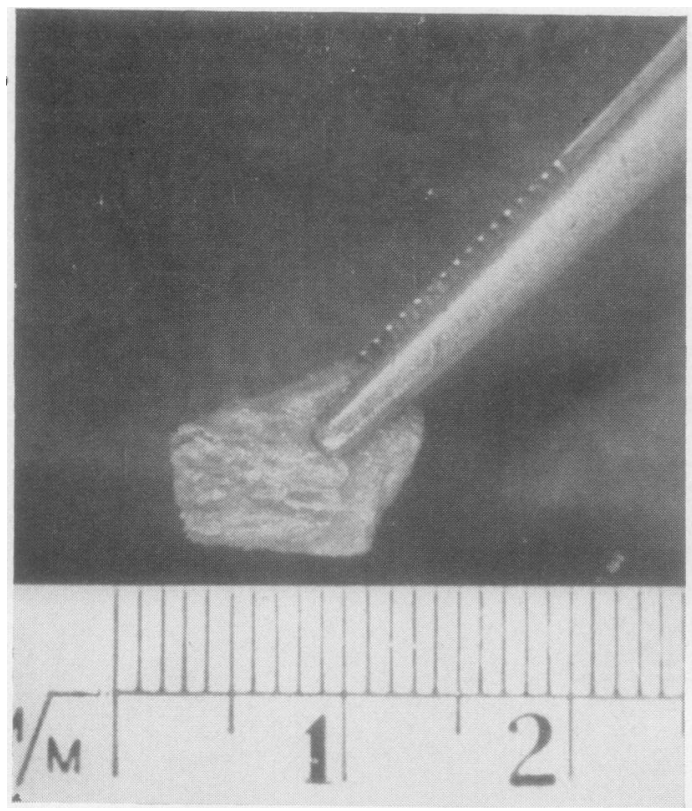

FIG. 5.-The bone fragment.

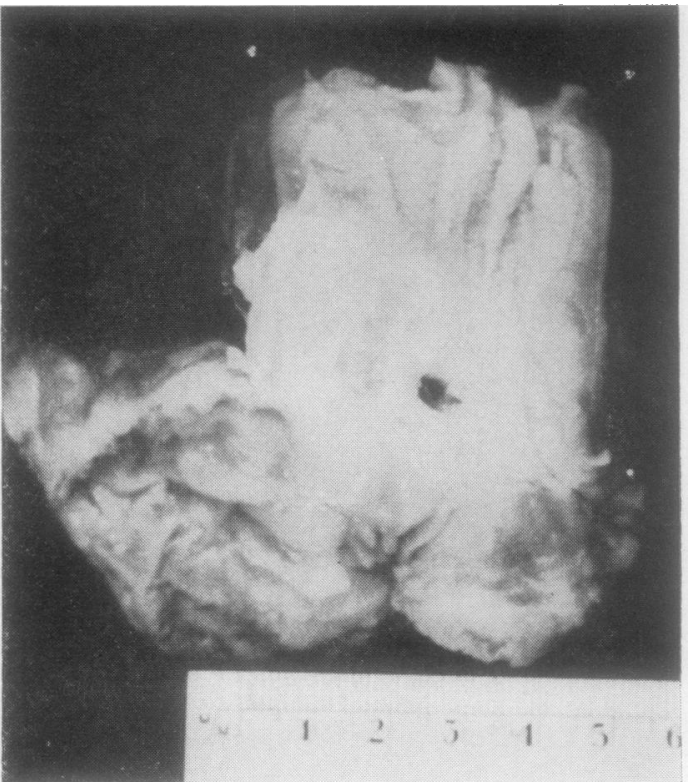

FIG. 3

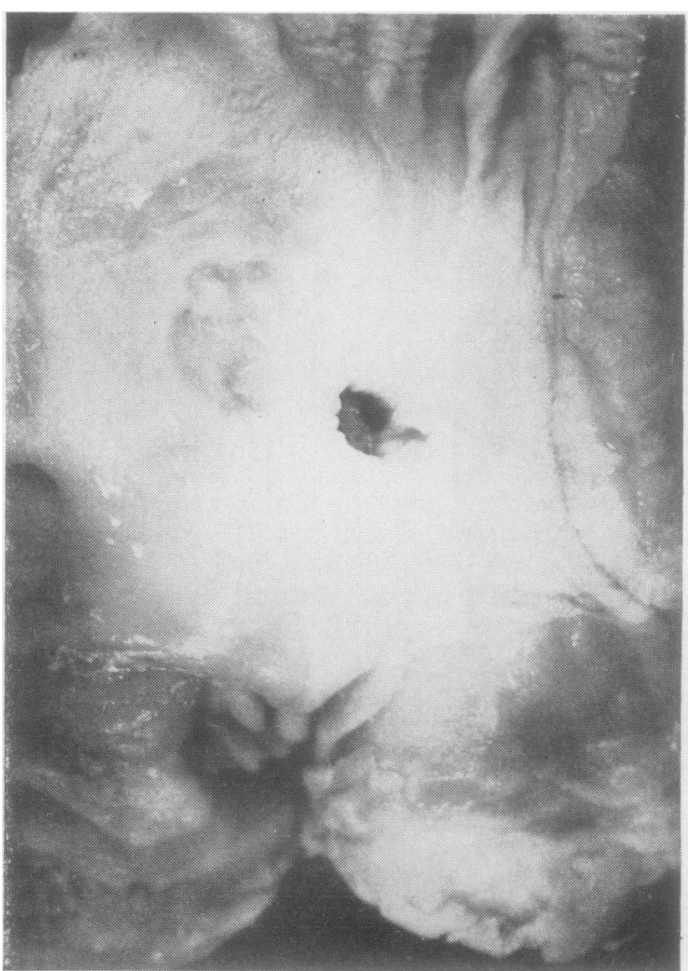

FIG. 4

FIGs. 3 and 4.-The oesophagus laid open aiong the lesser curvature. In Fig. 4 the edge of the piece of bone can be seen in the diverticulum. 
opening was seen on the left lateral wall (Figs. 3 and 4) and in the pouch a piece of bone was seen to be firmly lodged. The foreign body was pulled out with difficulty; it measured $1 \times 1 \times 0.5 \mathrm{~cm}$. (Fig. 5). The interior of the diverticulum was free from ulceration or growth. In retrospect, a filling defect in the radiograph of the bariumfilled diverticulum was appreciated. Section of the diverticulum showed well-formed muscle layers in its wall.

The patient was well when she returned six months later.

\section{Discussion}

Rokitansky is credited with the statement that pulsion or traction causes diverticulum of the alimentary tract. Barrett (1933) added the combined traction-pulsion variety. False or "functional" diverticulum has been described by Johnstone (1949) in the lower thoracic oesophagus during abnormal peristalsis. Diverticulum proximal to growth or benign stricture, though not common, has been reported. The epiphrenic diverticulum is idiopathic in origin.

Excellent reviews of this condition are available (Granet, 1933 ; Janes, 1946 ; Goodman and Parnes, 1952 ; Cornell, 1956 ; Shields and Anderson, 1959). Often the diverticulum projects to the right. The range in size and shape of 121 diverticula is given by Habein, Moersch, and Kirklin (1956b) and by Habein, Kirklin, Clagett, and Moersch (1956a). Men of middle age are predominantly affected.

The aetiology is not known. Dessecker in 1924 postulated the mechanical theory that the diverticulum is produced by the bending of the oesophagus to the left at the cardia. The present conception is that a congenital pouch becomes larger owing to increased intra-oesophageal pressure (pulsion). Shaw (1954) mentioned the "segmentation" of the circular muscle coat of the oesophagus (the blood vessels passing in the gaps between the segments) as a possible site of pouching. However, the large intentional incision of Heller's operation does not result in anything like a pulsion diverticulum. Another suggestion is that ageing leads to localized weakening of the muscle wall. The fact that the majority of patients are middle-aged or old lends support to this view. Epiphrenic diverticulum has, however, been reported in the newborn and in infants (references available in Shaw, 1954 ; Decker and Maytham, 1957).

This condition is rare. Harrington (1949) had only seen eight patients with epiphrenic diverticulum while operating on 216 patients with pharyngo-oesophageal diverticulum. Lahey and Warren (1954) had nine and 365 patients respectively ; Sweet (1956) ten and 67 ; Mustard (1957) eight and 67 (the latter including 14 epibronchial diverticula). However, Shaw (1954) quotes a French author's series in which $65 \%$ of the oesophageal diverticula were intrathoracic and only $35 \%$ were in the pharyngo-oesophageal region. Modern advances are cited as being responsible.

Symptomatology, beginning from nothing, runs the gamut of symptoms referable to the upper alimentary tract. When other conditions, such as hiatus hernia, are present in addition, it is difficult to trace the source of the symptoms (Habein et al., 1956b). One feature has been mentioned so frequently that it invites discussion. This is dysphagia, alone or with regurgitation of food. It was present in $65 \%$ of the patients in large series; almost all the single case reports (including ours) mention dysphagia as the single or primary reason why the patient consulted a doctor. In most of the patients the dysphagia had been present for many years; it was indistinguishable from that seen in achalasia. But these are two separate entities. The obstruction of a pure achalasia causes uniform proximal dilatation of the oesophagus. In our series of 58 patients with achalasia, all had moderate to severe dilatation of the oesophagus but none had a diverticulum. Johnstone (1949) has commented similarly. Pouching occurs only if conditions are suitable for its formation, and lower oesophageal "spasm" may play a part.

Asthmatic attacks (Nylander, 1952), chest pain with E.C.G. changes resembling coronary thrombosis (Julian, 1953), and "delayed drunkenness" (Trempe, 1955) have been reported. Complications such as ulceration, perforation, haemorrhage, and carcinoma are also known. Lung infection due to aspiration was reported by D'Abreu (1949).

Food debris in the diverticulum is an extremely common finding. But the only reported retained foreign body is that of Decker and Maytham (1957). A $2 \frac{1}{2}$-year-old child was examined because of regurgitation of food of four months' duration. Radiological studies by barium swallow showed a diverticulum in the posterior wall of the midthoracic oesophagus. Endoscopy revealed nothing further. The regurgitation lessened but reappeared after some months, necessitating another oesophagoscopy. This time a plastic rod, $20 \times 8 \times 2$ $\mathrm{mm}$., was seen in the oesophagus distal to the diverticulum and was removed. The child was free from symptoms afterwards. 
The need for diagnosis is one aspect on which all modern authors agree. Barium swallow and fluoroscopy are the first and final steps in reaching a diagnosis. Shaw (1954) discusses the help afforded by oesophagoscopy.

Generally it is easy to select the patients needing surgery by reviewing their symptoms. The early papers mention extrapleural diverticulectomy (in stages), diverticulopexy, and diverticulo-gastrostomy. Now the standard operation is transpleural diverticulectomy. Goodman and Parnes (1952) and DeBakey and Creech (1952) were the first to advocate thoraco-abdominal oesophago-gastrectomy and oesophago-gastrostomy. In our patient the hard foreign body led us to suspect an indurated growth together with an epiphrenic diverticulum. Even without this factor, excision and anastomosis was, we think, indicated.

\section{SUMMARY}

A case of epiphrenic diverticulum of the oesophagus with a piece of bone impacted in the diverticulum is reported. The literature is briefly reviewed, and this is the first report of such a case.

\section{REFERENCES}

Barrett, N. R. (1933). Lancet, 1, 1009.

Cornell, A. (1956). J. Mt Sinai Hosp., $23,40$.

D'Abreu, A. L. (1949). Brit. J. Radiol., 22, 423.

DeBakey, M. E., and Creech, O. (1952). J. thorac. Surg., 23, 486.

Decker, G. A. G., and Maytham, D. V. (1957). S. Afr. med. J., 31, 1096.

Goodman, H. I., and Parnes, I. H. (1952). J. thorac. Surg., 23, 145. Granet, E. (1933). Amer. J. Surg., 19, 259.

Habein, Jr., H. C., Kirklin, J. W., Clagett, O. T., and Moersch, H. J. (1956a). A.M.A. Arch. Surg., 72, 1018.

- Moersch, H. J., and Kirklin, J. W. (1956b). A.M.A. Arch. intern. Med., 97, 768.

Harrington, S. W. (1949). Ann. Surg., 129, 606.

Janes, R. M. (1946). Ibid., 124, 637.

Johnstone, A. S. (1949). Brit. J. Radiol., 22, 415

Julian, D. G. (1953). Lancet, 2, 915.

Lahey, F. H., and Warren, K. W. (1954). Surg. Gynec. Obstet., 98, 1. Mustard, R. A. (1957). Canad. med. Ass. J., 76, 822.

Nylander, P. E. A. (1952). Acta chir. scand., 103, 473.

Shaw, H. J. (1954). J. Laryngol., 68, 70.

Shields, T. W., and Anderson, M. C. (1959). Amer. J. dig. Dis., N.S., 4, 522 .

Sweet, R. H. (1956). Ann. Surg., 143, 433.

Trempe, F. (1955). Canad. med. Ass. J., 73, 38. 